\title{
Multi-ethnic Investigation of Risk and Immune Determinants of COVID-19 Outcomes
}

Tomi Jun ${ }^{1}$, Divij Mathew ${ }^{2,3}$, Navya Sharma ${ }^{4}$, Sharon Nirenberg ${ }^{5}$, Hsin-Hui Huang ${ }^{6}$, Patricia Kovatch $^{5}$, E. John Wherry ${ }^{2,3}$, Kuan-lin Huang ${ }^{7^{*}}$

${ }^{1}$ Division of Hematology and Medical Oncology, Tisch Cancer Institute, Icahn School of Medicine at Mount Sinai, New York, NY 10029, USA.

${ }^{2}$ Institute for Immunology, University of Pennsylvania Perelman School of Medicine, Philadelphia, PA, USA.

${ }^{3}$ Department of Systems Pharmacology and Translational Therapeutics, University of Pennsylvania Perelman School of Medicine, Philadelphia, PA, USA.

${ }^{4}$ University of California, Santa Barara, CA, USA.

${ }^{5}$ Scientific Computing, Icahn School of Medicine at Mount Sinai, New York, NY 10029, USA.

${ }^{6}$ Department of Population Health Science \& Policy, Icahn School of Medicine at Mount Sinai, New York, NY 10029, USA.

${ }^{7}$ Department of Genetics and Genomic Sciences, Center for Transformative Disease Modeling, Tisch Cancer Institute, Icahn Institute for Data Science and Genomic Technology, Icahn School of Medicine at Mount Sinai, New York, NY 10029, USA.

*Corresponding Author:

Kuan-lin Huang, Ph.D.

Department of Genetics and Genomic Sciences

Icahn School of Medicine at Mount Sinai

New York, NY 10029

Email: kuan-lin.huang@mssm.edu

Keywords: COVID-19; African American; Hispanic American; Interleukin-1beta; Hypoxia

Word count: 3,258 


\section{Abstract}

Objectives: To compare risk factors for COVID-19 mortality among hospitalized Hispanic, NonHispanic Black, and White patients.

Design: Retrospecitve cohort study

Setting: Five hosptials within a single academic health system

Participants: 3,086 adult patients with self-reported race/ethnicity information presenting to the emergency department and hospitalized with COVID-19 up to April 13, 2020.

Main outcome measures: In-hospital mortality

Results: While older age (multivariable $\mathrm{OR} 1.06,95 \% \mathrm{Cl} 1.05-1.07$ ) and baseline hypoxia (multivariable OR $2.71,95 \% \mathrm{CI}$ 2.17-3.36) were associated with increased mortality overall and across all races/ethnicities, Non-Hispanic Black (median age 67, IQR 58-76) and Hispanic (median age 63, IQR 50-74) patients were younger and had different comorbidity profiles compared to Non-Hispanic White patients (median age 73, IQR 62-84; $p<0.05$ for both comparisons). Among inflammatory markers associated with COVID-19 mortality, there was a significant interaction between the Non-Hispanic Black population and interleukin-1-beta (interaction p-value 0.04).

Conclusions: This analysis of a multi-ethnic cohort highlights the need for inclusion and consideration of diverse popualtions in ongoing COVID-19 trials targeting inflammatory cytokines. 
medRxiv preprint doi: https://doi.org/10.1101/2021.10.29.21265687; this version posted October 30, 2021. The copyright holder for this preprint (which was not certified by peer review) is the author/funder, who has granted medRxiv a license to display the preprint in perpetuity.

\author{
It is made available under a CC-BY-NC-ND 4.0 International license.
}




\section{Introduction}

Reports from the United States, the United Kingdom, and Brazil have highlighted racial disparities in the COVID-19 pandemic. $^{1-4}$ National studies from the UK and Brazil have found race to be an independent predictor of death. ${ }^{3,4}$ In the United States, Black and Hispanic individuals have disproportionately high rates of infection, hospitalization, and mortality. ${ }^{1,2,5,6}$ These disparities have been attributed to greater representation of Black and Hispanic persons in essential services, and a higher burden of comorbidities in minority communities, among others.

While Black and Hispanic individuals in the US have been disproportionately affected by the pandemic, the majority of published studies investigating COVID-19 mortality risk factors have been in cohorts of individuals with predominantly European or Asian ancestry. ${ }^{7-11}$ Few US studies have directly examined mortality risk factors and their effect sizes in Black or Hispanic compared to White individuals. ${ }^{1,12}$ Rigorous analysis to establish risk factors and molecular predictors for each population is urgently needed.

We sought to identify race/ethnic-specific clinical and immune factors of mortality using a diverse cohort of White, Black, and Hispanic COVID-19 patients admitted to a single health system in New York. In addition to baseline characterization, we conducted stratified and interaction term analyses to identify risk and immune factors that may affect outcomes of each patient population. The systematic analyses revealed population-specific effects of multiple risk factors that were previously unknown, highlighting the importance of including diverse patient populations and tailored consideration in precision medicine for COVID-19. 


\section{Results}

\section{Study population}

There were 4,997 adult patients with COVID-19-related emergency department (ED) visits on or before April $13^{\text {th }}, 2020$, of whom 3,086 (61.8\%) were hospitalized. Hospitalization rates were significantly lower for Non-Hispanic (NH) Black patients compared to other groups (NH Black 56.5\%; NH White 63.4\%; Hispanic 64.3\%, Asian 62.6\%; Other 63.6\%; $p<0.001$ ). Hospitalized patients were significantly older (median age 66 vs. 50, p<0.001) and were more likely to have comorbidities such as hypertension $(35.5 \%$ vs. $13.5 \%, p<0.001)$, diabetes $(24 \%$ vs. $7.8 \%$, $\mathrm{p}<0.001)$, and chronic kidney disease (11.9\% vs. 3.1\%, $p<0.001)$ (Supplemental Table 1). The clinical characteristics of non-hospitalized patients are summarized by race/ethnicity in

\section{Supplemental Table 2.}

The hospitalized cohort included 3,086 adult patients. We excluded 78 patients with missing race or ethnicity data, 144 Asian patients, and 458 patients with other or unspecified race/ethnicity from the comparative/stratified analyses based on power considerations (Figure 1). The remaining 2,406 patients were $37.1 \%$ Hispanic, $34.3 \%$ Non-Hispanic (NH) Black, and

\section{6\% NH White.}

Compared to NH White patients, NH Black and Hispanic patients were younger (median age 67 and 63 vs. 73, p<0.001 for both) (Table 1). NH Black patients were more likely to have hypertension (40.6\% vs $31.8 \%, p<0.001$ ), diabetes $(26.8 \%$ vs. $17.4 \%, p<0.001$ ), and chronic kidney disease $(16.1 \%$ vs. $8 \%, p<0.001)$ than $\mathrm{NH}$ White patients. Hispanic patients were more likely to have diabetes $(27.4 \%$ vs. $17.4 \%, p<0.001)$, chronic kidney disease $(13 \%$ vs. $8 \%$, 
medRxiv preprint doi: https://doi.org/10.1101/2021.10.29.21265687; this version posted October 30, 2021. The copyright holder for this preprint (which was not certified by peer review) is the author/funder, who has granted medRxiv a license to display the preprint in perpetuity. It is made available under a CC-BY-NC-ND 4.0 International license .

$\mathrm{p}=0.001)$, and chronic liver disease $(4.3 \%$ vs. $1.6 \%, p=0.003)$, compared to NH White patients.

$\mathrm{NH}$ White patients were more likely to have coronary artery disease $(17.1 \%$ vs. $12.2 \%$ and $11.3 \%, p=0.008$ vs. Black, $p=0.001$ vs. Hispanic) and atrial fibrillation $(12.3 \%$ vs. $5 \%$ and $4.5 \%$, $\mathrm{p}<0.001$ for both) than NH Black or Hispanic patients.

Table 1: Baseline demographic and clinical characteristics, by race/ethnicity

\begin{tabular}{|c|c|c|c|}
\hline & $\begin{array}{l}\text { NH White } \\
(\mathrm{N}=689)\end{array}$ & $\begin{array}{l}\text { NH Black } \\
(\mathrm{N}=825)\end{array}$ & $\begin{array}{l}\text { Hispanic } \\
(\mathrm{N}=892)\end{array}$ \\
\hline Age (yrs) & $73(62-84)$ & $67(58-76)^{\dagger}$ & $63(50-74)^{\dagger}$ \\
\hline $\begin{array}{l}\text { Mount Sinai Brooklyn } \\
\text { (MSB) }\end{array}$ & $156(22.6 \%)$ & $258(31.3 \%)^{\dagger}$ & $17(1.9 \%)^{\dagger}$ \\
\hline $\begin{array}{l}\text { Mount Sinai Queens } \\
\text { (MSQ) }\end{array}$ & $138(20 \%)$ & $61(7.4 \%)^{\dagger}$ & $271(30.4 \%)^{\dagger}$ \\
\hline $\begin{array}{l}\text { Mount Sinai Morningside } \\
\text { (MSSL) }\end{array}$ & $51(7.4 \%)$ & $199(24.1 \%)^{\dagger}$ & $216(24.2 \%)^{\dagger}$ \\
\hline Mount Sinai West (MSW) & $120(17.4 \%)$ & $65(7.9 \%)^{+}$ & $100(11.2 \%)^{\dagger}$ \\
\hline $\begin{array}{l}\text { The Mount Sinai Hospital } \\
\text { (MSH) }\end{array}$ & $224(32.5 \%)$ & $242(29.3 \%)$ & $288(32.3 \%)$ \\
\hline Current smoker* & $22(3.2 \%)$ & $43(5.2 \%)$ & $25(2.8 \%)$ \\
\hline Former smoker* & $147(21.3 \%)$ & $187(22.7 \%)$ & $190(21.3 \%)$ \\
\hline Never smoker* & 375 (54.4\%) & $437(53 \%)$ & $478(53.6 \%)$ \\
\hline Hypertension & $219(31.8 \%)$ & $335(40.6 \%)^{\dagger}$ & $318(35.7 \%)$ \\
\hline Diabetes & $120(17.4 \%)$ & $221(26.8 \%)^{\dagger}$ & $244(27.4 \%)^{\dagger}$ \\
\hline Coronary artery disease & $118(17.1 \%)$ & $101(12.2 \%)^{\dagger}$ & $101(11.3 \%)^{\dagger}$ \\
\hline Heart failure & $59(8.6 \%)$ & $71(8.6 \%)$ & $60(6.7 \%)$ \\
\hline Atrial fibrillation & $85(12.3 \%)$ & $41(5 \%)^{\dagger}$ & $40(4.5 \%)^{\dagger}$ \\
\hline Chronic kidney disease & $55(8 \%)$ & $133(16.1 \%)^{\dagger}$ & $116(13 \%)^{\dagger}$ \\
\hline COPD/asthma & $60(8.7 \%)$ & 75 (9.1\%) & $84(9.4 \%)$ \\
\hline Obesity & $50(7.3 \%)$ & 75 (9.1\%) & $80(9 \%)$ \\
\hline Cancer & $52(7.5 \%)$ & $63(7.6 \%)$ & $57(6.4 \%)$ \\
\hline Chronic liver disease & $11(1.6 \%)$ & $24(2.9 \%)$ & $38(4.3 \%)^{\dagger}$ \\
\hline Obstructive sleep apnea & $15(2.2 \%)$ & $18(2.2 \%)$ & $21(2.4 \%)$ \\
\hline HIV & $12(1.7 \%)$ & $23(2.8 \%)$ & $13(1.5 \%)$ \\
\hline Temperature $\left({ }^{\circ} \mathrm{F}\right)$ & $98.7(98-99.9)$ & $98.9(98.1-100.1)^{\dagger}$ & $99(98.3-100.4)^{\dagger}$ \\
\hline Heart rate (bpm) & $91(79-106)$ & $97(85-110)^{\dagger}$ & $99(86-113)^{\dagger}$ \\
\hline $\begin{array}{l}\text { Systolic blood pressure } \\
\text { (mmHg) }\end{array}$ & $129(114-146)$ & $131(116-148)$ & $128(115-144)$ \\
\hline Respiratory rate (bpm) & $20(18-22)$ & $20(18-22)$ & $20(18-22)$ \\
\hline Oxygen sat. <92\% & $184(26.7 \%)$ & $149(18.1 \%)^{\dagger}$ & $257(28.8 \%)$ \\
\hline
\end{tabular}


Values represent count (\%) or median (IQR) for categorical and continuous variables, respectively. ${ }^{\dagger}: \mathrm{p}<0.05$ compared to White. *: $22 \%$ missing values

These results demonstrate differences in the distributions demographic and clincial COVID-19 mortality risk factors by race/ethnicity.

Population-specific clinical factors associated with death

Unadjusted mortality rates were lower among NH Black $(27.5 \%$ vs. $34.1 \%, p=0.006)$ and Hispanic ( $23.9 \%$ vs. $34.1 \%, p<0.001$ ) patients compared to NH White patients. Rates of intensive care were not significantly different between NH Black and NH White $(19.8 \%$ vs $21.5 \%, p=0.44)$ or Hispanic and NH White $(23.4 \%$ vs $21.5 \%, p=0.36)$ patients.

We first evaluated the association of demographic, clinical, and laboratory variables with inhospital mortality (Table 2, Supplemental Table 4 \& 5). In a univariate analysis, NH Black (OR 0.73, 95\% Cl 0.59-0.91) and Hispanic (OR 0.61, 95\% Cl 0.49-0.76) populations were associated with lower mortality compared to NH White. However, race/ethnicity was not an independent predictor of mortality after adjusting for age, sex, comorbidities, and baseline hypoxia (oxygen saturation $<92 \%$ at the first measurement of the clinical encounter) in this cohort (Black HR 1.03, 95\% Cl 0.80-1.32; Hispanic $\mathrm{HR}$ 0.94, 95\% Cl 0.73-1.21) (Figure 2A). Our finding is consistent with several cohort studies in the US, ${ }^{1,13,14}$ although UK and Brazil studies have reported race as an independent predictor of mortality, ${ }^{3,4}$ possibly due to population differences.

Table 2: Multivariable model predicting in-hospital mortality, stratified by race/ethnicity 


\begin{tabular}{|c|c|c|c|c|}
\hline Variable & $\begin{array}{l}\text { NH White OR } \\
(95 \% \mathrm{Cl})\end{array}$ & $\begin{array}{c}\text { NH Black OR } \\
(95 \% \mathrm{Cl})\end{array}$ & $\begin{array}{c}\text { Hispanic OR } \\
(95 \% \mathrm{CI})\end{array}$ & $\begin{array}{c}\text { All patients OR } \\
(95 \% \mathrm{Cl})\end{array}$ \\
\hline Male & $1.51(1.03-2.22)$ & $1.55(1.09-2.19)$ & $1.04(0.73-1.49)$ & $1.29(1.05-1.58)$ \\
\hline Age (yrs) & $1.07(1.05-1.09)$ & $1.06(1.04-1.07)$ & 1.05 (1.04-1.07) & $1.06(1.05-1.07)$ \\
\hline Race: NH White & Reference & Reference & Reference & Reference \\
\hline Race: NH Black & NA & NA & NA & $1.03(0.80-1.32)$ \\
\hline Race: Hispanic & NA & NA & NA & $0.94(0.73-1.21)$ \\
\hline Manhattan facility & $0.45(0.31-0.64)$ & $0.53(0.37-0.75)$ & $0.62(0.43-0.89)$ & $0.53(0.43-0.65)$ \\
\hline Hypertension & $0.86(0.56-1.33)$ & $0.69(0.45-1.06)$ & $0.78(0.51-1.2)$ & $0.77(0.61-0.98)$ \\
\hline Diabetes & 0.99 (0.61-1.63) & $1.67(1.09-2.58)$ & $1.21(0.79-1.83)$ & $1.26(0.98-1.63)$ \\
\hline $\begin{array}{l}\text { Coronary artery } \\
\text { disease }\end{array}$ & $0.98(0.58-1.65)$ & $1.14(0.67-1.93)$ & $0.10(0.57-1.73)$ & $1.03(0.76-1.39)$ \\
\hline Heart failure & $0.94(0.48-1.85)$ & $1.11(0.6-2.06)$ & $1.14(0.55-2.36)$ & $1.05(0.72-1.54)$ \\
\hline Atrial fibrillation & $1.15(0.66-2.02)$ & $1.27(0.62-2.59)$ & $1.99(0.97-4.11)$ & $1.38(0.95-2.00)$ \\
\hline Chronic kidney disease & $2.25(1.18-4.28)$ & $1.71(1.06-2.77)$ & $1.38(0.80-2.38)$ & $1.70(1.25-2.31)$ \\
\hline COPD/asthma & $0.9(0.48-1.68)$ & $0.80(0.42-1.54)$ & $0.58(0.32-1.06)$ & $0.75(0.52-1.07)$ \\
\hline Obesity & $0.72(0.33-1.60)$ & $1.33(0.69-2.58)$ & $1.59(0.86-2.91)$ & $1.25(0.86-1.83)$ \\
\hline Cancer & $0.95(0.49-1.85)$ & $1.15(0.61-2.16)$ & $1.65(0.88-3.07)$ & $1.25(0.86-1.8)$ \\
\hline Oxygen sat. $<92 \%$ & $2.377(1.6-3.54)$ & $2.51(1.69-3.75)$ & $3.22(2.24-4.61)$ & $2.71(2.17-3.36)$ \\
\hline
\end{tabular}

Previous patient cohort analyses rarely considered race/ethnic-specific risk factors, which require stratified modeling within each population cohort. We conducted stratified analyses within ethnic groups to determine the population-specific effect sizes of clinical factors and comorbidity. Diabetes was associated with an odds ratio of $1.67(95 \% \mathrm{Cl} 1.09-2.58)$ in the stratified NH Black population, and an odds ratio of 0.99 (95\% $\mathrm{Cl} 0.61-1.63)$ in the NH White population (Figure 2B). Obesity was associated with an odds ratio of $1.33(95 \% \mathrm{Cl} 0.69-2.58)$ in $\mathrm{NH}$ Black, compared to an odds ratio of 0.72 (95\% $\mathrm{Cl} 0.33-1.60)$ in $\mathrm{NH}$ White (Figure 2B). 
medRxiv preprint doi: https://doi.org/10.1101/2021.10.29.21265687; this version posted October 30, 2021. The copyright holder for this preprint (which was not certified by peer review) is the author/funder, who has granted medRxiv a license to display the preprint in perpetuity.

It is made available under a CC-BY-NC-ND 4.0 International license .

Increased age and baseline hypoxia were consistently associated with increased mortality across all three populations (Supplemental Table 6). Altogether, these results highlight the shared and specific clinical risk factors of COVID-19 mortality across populations.

\section{Baseline laboratory values}

We analyzed baseline lab values among patients admitted to the largest site in our dataset, the Mount Sinai Hospital (MSH). This site had the most complete records for routine and inflammatory lab values. We defined baseline labs as the first lab value within 24 hours of the start of the encounter.

Among common lab values, Hispanic patients had higher baseline alanine aminotransferase values (ALT, 33 vs. $28 \mathrm{U} / \mathrm{L}, \mathrm{p}=0.03$ ) than $\mathrm{NH}$ White patients (Table 3), consistent with the increased prevalence of chronic liver disease among Hispanic patients.

Table 3: Baseline laboratory values among patients admitted to The Mount Sinai Hospital, by race/ethnicity

\begin{tabular}{|c|c|c|c|c|}
\hline Laboratory test & $\begin{array}{l}\text { Evaluable } \\
\text { Patients }\end{array}$ & NH White & NH Black & Hispanic \\
\hline $\begin{array}{l}\text { White blood cells, } \\
10^{\wedge} 3 / \mathrm{uL}\end{array}$ & 984 & $6.5(5-9.825)$ & $6.3(4.9-9.2)$ & $6.4(5-9.1)$ \\
\hline Hemoglobin, g/dL & 985 & $\begin{array}{c}13.15(12- \\
14.125)\end{array}$ & $12.6(10.9-13.8)^{\dagger}$ & $13.2(11.4-14.5)$ \\
\hline Platelets, $10^{\wedge} 3 / \mathrm{uL}$ & 980 & $205(159.5-256)$ & $203(157-264.25)$ & $212.5(165.25-279.5)$ \\
\hline Sodium, $\mathrm{mmol} / \mathrm{L}$ & 984 & $136(134-139)$ & $137(135-140)^{\dagger}$ & 137 (134 - 139.25) \\
\hline Potassium, $\mathrm{mmol} / \mathrm{L}$ & 941 & $4(3.7-4.55)$ & $4.3(3.8-4.8)^{\dagger}$ & $4.2(3.8-4.6)$ \\
\hline Chloride, $\mathrm{mmol} / \mathrm{L}$ & 984 & $101(98-104)$ & $102(97.25-105)$ & $102(98-105)$ \\
\hline $\begin{array}{l}\text { Blood urea nitrogen, } \\
\mathrm{mg} / \mathrm{dL}\end{array}$ & 984 & $17(12-28)$ & $22(14-46)^{\dagger}$ & $15(10-27)^{\dagger}$ \\
\hline Creatinine, $\mathrm{mg} / \mathrm{dL}$ & 985 & $0.88(0.7-1.22)$ & $1.25(0.9-2.705)^{\dagger}$ & $0.87(0.67-1.2325)$ \\
\hline $\begin{array}{l}\text { Aspartate } \\
\text { aminotransferase, } \mathrm{U} / \mathrm{L}\end{array}$ & 915 & $38(29-63)$ & $40(28-59)$ & $43(30-68.25)$ \\
\hline $\begin{array}{l}\text { Alanine } \\
\text { aminotransferase, } \mathrm{U} / \mathrm{L}\end{array}$ & 958 & $28(18-49)$ & $26(16.5-41.5)$ & $33(20-63)^{\dagger}$ \\
\hline
\end{tabular}




\begin{tabular}{|c|c|c|c|c|}
\hline Total bilirubin, $\mathrm{mg} / \mathrm{dL}$ & 966 & $0.6(0.5-0.8)$ & $0.6(0.4-0.9)$ & $0.6(0.4-0.8)$ \\
\hline Albumin, $\mathrm{g} / \mathrm{dL}$ & 969 & $3.1(2.7-3.5)$ & $3.2(2.8-3.55)$ & $3.3(2.9-3.6)^{\dagger}$ \\
\hline D-dimer, ug/mL FEU & 755 & $\begin{array}{c}1.25(0.78- \\
2.0475)\end{array}$ & $1.59(0.78-2.795)$ & $1.15(0.6575-2.2125)$ \\
\hline Ferritin, $\mathrm{ng} / \mathrm{mL}$ & 904 & $\begin{array}{c}679.5(354.75- \\
1423)\end{array}$ & $717(328-2124)$ & 665 (275.5 - 1649.75) \\
\hline $\begin{array}{l}\text { Ferritin, times upper } \\
\text { limit of normal }\end{array}$ & 904 & $\begin{array}{c}2.24(1.190625- \\
4.76625)\end{array}$ & $3.16(1.18-6.37)^{\dagger}$ & $2.66(1.15-5.15)$ \\
\hline Procalcitonin, $\mathrm{ng} / \mathrm{mL}$ & 914 & $\begin{array}{c}0.13(0.06- \\
0.375)\end{array}$ & $0.29(0.09-0.855)^{\dagger}$ & $0.17(0.08-0.5075)$ \\
\hline $\begin{array}{l}\text { Lactate dehydrogenase, } \\
\mathrm{U} / \mathrm{L}\end{array}$ & 854 & $405(326-488)$ & $\begin{array}{c}396.5(312.5- \\
574.75)\end{array}$ & $388(296-525)$ \\
\hline $\mathrm{C}$-reactive protein, $\mathrm{mg} / \mathrm{L}$ & 903 & $\begin{array}{c}119.35(68.625- \\
203.475)\end{array}$ & $\begin{array}{c}100.25(49.45- \\
173.45)\end{array}$ & $100.4(54.125-193.575)$ \\
\hline $\begin{array}{l}\text { Interleukin-1 beta, } \\
\mathrm{pg} / \mathrm{mL}\end{array}$ & 418 & $0.5(0.375-0.7)$ & $0.6(0.4-0.9)$ & $0.5(0.4-0.8)$ \\
\hline Interleukin-6, $\mathrm{pg} / \mathrm{mL}$ & 583 & $84.3(44.8-149)$ & $69.05(39.9-120.75)$ & $68.2(40-135)$ \\
\hline Interleukin-8, pg/mL & 521 & $\begin{array}{c}41.25(29.725- \\
58.7)\end{array}$ & $\begin{array}{c}43.95(24.725- \\
70.15)\end{array}$ & $43.85(28.025-64)$ \\
\hline $\begin{array}{l}\text { Tumor necrosis factor- } \\
\text { alpha, } \mathrm{pg} / \mathrm{mL}\end{array}$ & 522 & $24(18.425-33)$ & $26.35(17.6-45.4)$ & $22.3(16.925-32.125)$ \\
\hline
\end{tabular}

Among inflammatory lab markers, NH Black patients had higher initial levels of procalcitonin (0.29 vs. $0.13 \mathrm{ng} / \mathrm{mL}, \mathrm{p}<0.001$ ), and more abnormal ferritin levels (3.16 vs. 2.24 times upper limit of normal, $\mathrm{p}=0.03$ ) compared to $\mathrm{NH}$ White patients (Table 3). There were no significant differences in baseline d-dimer, lactate dehydrogenase (LDH), C-reactive protein (CRP), interleukin-1-beta (IL-1B), interleukin-6 (IL-6), interleukin-8 (IL-8), or tumor necrosis factoralpha (TNFa) levels. Thus, population-specific associations identified for these immune factors would indicate contributions from their relative differences between patients of different outcomes within a population rather than baseline differences across populations.

Population-specific immune factors associated with clinical outcomes 
We next conducted a multi-ethnic analysis to identify immune markers associated with patient outcomes in the MSH cohort. Using multivariate models adjusting for age, sex, and hypoxia, we identified CRP (OR 1.39, 95\% Cl 1.16-1.68), albumin (OR 0.75, 95\% Cl 0.61-0.91), IL-6 (OR 1.43, 95\% Cl 1.12-1.82), WBC (OR 1.35, 95\% Cl 1.08-1.65), and LDH (OR 1.34, 95\% Cl 1.07-1.68) as independent predictors of mortality (Supplemental Table 7).

To identify immune markers showing population-specificity in predicting COVID-19 outcomes, we applied the multivariate regression model in each population-stratified cohort. Elevated levels of IL-1B were associated with a higher risk of mortality in Black (OR 2.35, 95\% CI 1.134.86) compared to White patients (OR 0.78, 95\% CI 0.41-1.51) (Figure 3, Supplemental Table 7). Increased procalcitonin levels were associated with an odds ratio of $2.65(95 \% \mathrm{Cl} 0.88-7.96)$ in Hispanic patients, compared to an odds ratio of 0.98 (95\% $\mathrm{Cl} 0.58-1.66)$ among $\mathrm{NH}$ White patients. Increased IL-8 levels were associated with an odds ratio of 1.51 (95\% Cl $0.59-3.86)$ among Hispanic patients, and an odds ratio of 8.76 (95\% $\mathrm{Cl} 0.95-80.7)$ among White patients (Supplemental Table 7). To validate the population-specificity of these COVID-19 mortalityassociated immune markers, we further utilized a multivariate model including interaction terms, finding a significant interaction between NH Black and IL-1B ( $p=0.04)$ and a suggestive but non-significant interactions between Hispanic and procalcitonin ( $p=0.07)$ and IL-8 ( $p=0.09)$ compared to NH White (Supplemental Table 6).

Next, we sought to validate the immune marker findings of the MSH cohort in an independent dataset. We utilized immunoprofiling data from the University of Pennsylvania cohort ${ }^{15}$ to compare levels of serum cytokines and immunologic markers between diverse patient 
populations vs. heatlhy and recovered donors. Among the COVID-19 patients with available race/ethnicity data, eight were NH Black, three were NH White, and four were Asian. Additionally, there were ten healthy donors (HDs) and twelve recovered donors (RDs) with no available race/ethnicity data.

We used the non-parametric Mood's median test to detect potential population differences in the median values of 13 measured immune markers against the combined cohort of HDs and RDs (HDs/RDs, Supplemental Table 8). NH Black patients had significantly higher median IL-6 (37.1 vs 2.59, p=0.003) and IP10 (227 vs 55.6, p=0.006), and lower median IL12p70 (1.98 vs 3.41, $p=0.004$ ) levels than HDs/RDs. IP10 was also found to be significant when comparing NH White or Asian patients vs. HDs/RDs ( $p<0.05)$. Median IL-1B was 4.13 in NH Black patients compared to 2.66 in $\mathrm{HDs} / \mathrm{RDs}(\mathrm{p}=0.115)$, providing a suggestive yet non-significant association to the finding in the MSH cohort.

\section{Discussion}

Racial disparities in COVID-19 infections and outcomes have become apparent in both the US and elsewhere..$^{1-4}$ The causes of these disparities are complex and multifactorial and must be considered in the context of the social determinants of health. ${ }^{4,16}$

In this study, set in New York City during the height of the initial COVID-19 surge, we describe the characteristics and outcomes of a diverse cohort including substaintial numbers of $\mathrm{NH}$ White, NH Black, and Hispanic patients. The three groups differed significantly in demographic and clinical factors. White patients were older and showed higher rates of cardiovascular disease such as coronary artery disease atrial fibrillation. NH Black and Hispanic patients were 
younger, and had different comorbidity profiles, e.g. hypertension, diabetes, chronic kidney disease, and chronic liver disease.

Unadjusted in-hospital mortality was highest in NH White patients, but multivariable analysis showed that race/ethnicity was not an independent predictor of mortality in this cohort. It remains unclear whether race and ethnicity are independent risk factors for COVID-19 mortality after adjusting for confounding factors. Large national-level studies in the UK and Brazil have reported race as an independent predictor of mortality, ${ }^{3,4}$ whereas smaller studies in the US have not, ${ }^{1,13,14}$ possibly due to statistical power or population differences. Changes in clinical management and outcomes of COVID-19 over the course of the pandemic may also complicate comparisons of results from different time periods. ${ }^{17}$ In this New York City patient population, race/ethnicity was not an independent predictor for mortality.

In addition to describing this cohort, we aimed to test established COVID-19 risk factors for race/ethnicity-specific effects. Despite recapitulating several known risk factors, such as age, male sex, and hypoxia, we found only suggestive but non-significant interactions between Black race, diabetes and obesity, both of which tended to increase the mortality risk of Black patients to a greater degree than White patients. Notably, when analyzing inflammatory markers for their association with mortality, we found a significant interaction between the NH Black population and the inflammatory cytokine IL-1B.

Excessive inflammation has emerged as an important aspect of COVID-19 pathophysiology, and the anti-inflammatory steroid dexamethasone has been shown to improve outcomes among those with severe disease. ${ }^{18}$ The interaction between the NH Black population and IL-1B raises 
the possibility that differences in immunity may contribute to worse outcomes in some patients. Black Americans are at higher risk of autoimmune conditions such as systemic lupus erythematosus and lupus nephritis compared to White Americans, differences which can be linked in some cases to specific polymorphisms which are more common in African Americans. $^{19-22}$

Interleukin-1-beta (IL-1B) is a pro-inflammatory cytokine that plays a role in both physiologic and pathologic inflammation. IL-1 inhibitors such as anakinra and canakinumab have been developed to target IL-1 in autoimmune diseases such as rheumatoid arthritis and Still's disease. These agents are also being actively investigated as COVID-19 treatments. Thus far, two randomized studies have found no clinical benefit from IL-1 inhibitors in COVID-19. ${ }^{23,24}$ However, these studies have not reported analyses taking race/ethnicity into account.

The strengths of our database include its size and the inclusion of $37.1 \%$ Hispanic patients, a vulnerable population in this pandemic which, has been underrepresented in the literature to date. Additionally, our near-complete follow-up of the cohort's hospital outcomes (99.3\%) strengthens the validity of our findings.

In conclusion, our analysis of a diverse cohort drawn from the New York metropolitan area highlights both similarities and important differences across racial/ethnic groups in risk factors for death among hospitalized COVID-19 patients. The findings identified across populations call for conscious inclusion in future cohort studies and clinical trials to ensure the efficacy of potential diagnostics and treatments across diverse individuals. 


\section{Limitations of the study}

Our study has limitations that warrant specific mention. The cytokine analysis was limited to only a subset of the population and should be considered exploratory. We were not able to control for other comorbidities which may have influenced cytokine levels (e.g. diabetes and IL1B). ${ }^{25}$ The dataset was derived from the electronic health record database without manual review, which may limit the completeness of comorbidity labels. Race and ethnicity were selfreported and were missing or unspecified in $17.4 \%$ of the initial cohort. The subset of patients with cytokine data was limited in number and models testing interactions Causal mechanisms underlying the correlations identified in this retrospective analysis remain to be elucidated.

\section{$\underline{\text { Methods }}$}

Study setting

The study was conducted within the Mount Sinai Health System, which is an academic healthcare system comprising 8 hospitals and more than 410 ambulatory practice locations in the New York metropolitan area. This analysis involves patients who presented to five hospitals: The Mount Sinai Hospital (1,134 beds), Mount Sinai West (514 beds), and Mount Sinai Morningside (495 beds) in Manhattan; Mount Sinai Brooklyn (212 beds); and Mount Sinai Queens (235 beds).

\section{Data sources}

Data were captured by the Epic electronic health record (Epic Systems, Verona, WI), and directly extracted from Epic's Clarity and Caboodle servers. This de-identified dataset was 
developed and released by the Mount Sinai Data Warehouse (MSDW) team, with the goal of encompassing all COVID-19 related patient encounters within the Mount Sinai system, accompanied by selected demographics, comorbidities, vital signs, medications, and lab values. As part of de-identification, all patients over the age of 89 had their age set to 90.

This study utilized de-identified data extracted from the electronic health record and as such was considered non-human subject research. Therefore, this study was granted an exemption from the Mount Sinai IRB review and approval process.

\section{Patient population and definitions}

The MSDW dataset captured any patient encounters at a Mount Sinai facility with any of the following: a COVID-19 related encounter diagnosis, a COVID-19 related visit type, a SARS-CoV-2 lab order, a SARS-CoV-2 lab result, or a SARS-CoV-2 lab test result from the New York State Department of Health's Wadsworth laboratory. For this study, we identified patients with COVID-19 related visits to to the emergency department on or before April $13^{\text {th }}, 2020$ and selected patients who were admitted. We followed their hospitalization outcomes through June $2^{\text {nd }}, 2020$.

Our analysis was limited to adults over 18 years old who were hospitalized for COVID-19 through a Mount Sinai emergency department. Self-reported race and ethnicity were classified into 3 mutually exclusive categories: Non-Hispanic White (White), Non-Hispanic Black (Black), and Hispanic (Supplemental Table 1). COVID-19 positivity was determined by a positive or presumptive positive result from a nucleic acid-based test for SARS-CoV-2 in nasopharyngeal or oropharyngeal swab specimens. Baseline vital signs were the first documented vital signs for 
the encounter. Hypoxia was defined as an oxygen saturation less than $92 \%$. We defined baseline labs as the first lab value within 24 hours of the start of the encounter.

University of Pennsylvania cohort:

Patients in the University of Pennsylvania cohort were identified based on a postive SARS-CoV-2 PCR test. Patients were screened and consented within 72 hours of hospitalization. Clinical data were collected from electronic medical records into standardized case reports. Healthy donors had no prior diagnosis or symptoms consident with COVID-19. Recovered donors were adults with a self reported positive COVID-19 PCR test who recovered as defined by the Centers for Disease Control. Cyotkine levels were measured from peripheral blood plasma using a custom human cytokine 31-plex panel (EMD Millipore Corporation, SPRCUS707), as described in Divij et al. $^{15}$

Logistic regression

The primary outcome was in-hospital mortality. Univariable and multivariable logistic regression were used to identify factors associated with death. Race/ethnicity-specific risk factors were identified by 1) constructing stratified models for each racial category, and 2) constructing models including interaction terms between race/ethnicity and other covariates. Separate interaction models were created to test the interactions of either Hispanic ethnicity or Black race with other covariates. Interactions were compared against White race as the reference group. 
We analyzed demographic factors, comorbidities, initial vital signs, baseline lab values, and treatment facility site (Manhattan vs. Brooklyn/Queens) as covariates. There was minimal clustering of outcomes by treatment site (ICC $(\rho)=0.026)$, and this was modeled as a fixed effect. Covariates were chosen a priori based on prior reports. We report the odds ratios derived from the coefficients of each model, along with the Wald-type confidence interval, and p-values.

\section{Laboratory value analysis}

Markers of inflammation, such as C-reactive protein (CRP), ferritin, and $d$-dimer, have been proposed as being correlated with COVID-19 severity. However, the missingness of these lab values varied across sites. Given the possibility of confounding by indication (if providers ordered these labs in more acutely ill patients), we limited the analyses involving lab tests to those obtained at the largest site (The Mount Sinai Hospital) and which had less than $15 \%$ missing values at that site. The cytokines interleukin-1-beta, interleukin-6, interleukin-8, and tumor necrosis factor-alpha were exempted from this threshold because they were obtained on a subset of COVID-19 patients in the context of a study with broad inclusion criteria. ${ }^{26,27}$

To test the associations of these lab values with mortality, we tested each lab test in race/ethnicity-stratified multivariable logistic regression models adjusting for age, sex, and hypoxia. The number of covariates in the model was limited due to the reduced sample size. Labs were standardized to a mean of 0 and a standard deviation of 1 prior to regression analysis.

Statistical analysis 
Patient characteristics and baseline vitals and labs were described using medians and ranges for continuous variables, and proportions for categorical variables. Continuous variables were compared using the Wilcoxon rank-sum test, and categorical variables were compared using Fisher's exact test. All statistical analyses and data visualizations were carried out using R 4.0.0 (The R foundation, Vienna, Austria), along with the tidyverse, ggpubr, forestplot, and Hmisc packages. Statistical significance was defined as $p<0.05$.

Patient and public involvement

Patients and the public were not involved in the design or conduct of this study.

\section{Acknowledgment}

We dedicate this work to the frontline health workers and staff of the Mount Sinai Healthcare System.

\section{Funding}

This work was supported by NIGMS R35GM138113 to K.H.

\section{Competing financial interests}

E.J.W. has consulting agreements with and/or is on the scientific advisory board for Merck, Elstar, Janssen, Jounce, Related Sciences, Synthekine and Surface Oncology. E.J.W. is a founder of Surface Oncology and Arsenal Biosciences. E.J.W. has a patent licensing agreement on the PD-1 pathway with Roche/Genentech. 
medRxiv preprint doi: https://doi.org/10.1101/2021.10.29.21265687; this version posted October 30, 2021. The copyright holder for this preprint (which was not certified by peer review) is the author/funder, who has granted medRxiv a license to display the preprint in perpetuity.

\section{References}

1 Price-Haywood EG, Burton J, Fort D, Seoane L. Hospitalization and Mortality among Black Patients and White Patients with Covid-19. New England Journal of Medicine 2020; 382: 2534-43.

2Jr RAO, Gebeloff R, Lai KKR, Wright W, Smith M. The Fullest Look Yet at the Racial Inequity of Coronavirus. The New York Times. 2020; published online July 5. https://www.nytimes.com/interactive/2020/07/05/us/coronavirus-latinos-african-americanscdc-data.html (accessed Aug 1, 2020).

3 Baqui P, Bica I, Marra V, Ercole A, van der Schaar M. Ethnic and regional variations in hospital mortality from COVID-19 in Brazil: a cross-sectional observational study. Lancet Glob Health 2020; 8: e1018-26.

4 Williamson EJ, Walker AJ, Bhaskaran K, et al. OpenSAFELY: factors associated with COVID-19 death in 17 million patients. Nature 2020; : 1-11.

$5 \mathrm{Hsu} \mathrm{HE}$, Ashe EM, Silverstein $\mathrm{M}$, et al. Race/Ethnicity, Underlying Medical Conditions, Homelessness, and Hospitalization Status of Adult Patients with COVID-19 at an Urban SafetyNet Medical Center - Boston, Massachusetts, 2020. MMWR Morb Mortal Wkly Rep 2020; 69: 864-9.

6 Holtgrave DR, Barranco MA, Tesoriero JM, Blog DS, Rosenberg ES. Assessing racial and ethnic disparities using a COVID-19 outcomes continuum for New York State. Ann Epidemiol 2020; 48: 9-14.

7 Petrilli CM, Jones SA, Yang J, et al. Factors associated with hospital admission and critical illness among 5279 people with coronavirus disease 2019 in New York City: prospective cohort study. BMJ 2020; 369. DOI:10.1136/bmj.m1966.

8Docherty AB, Harrison EM, Green CA, et al. Features of 20133 UK patients in hospital with covid-19 using the ISARIC WHO Clinical Characterisation Protocol: prospective observational cohort study. BMJ 2020; 369. DOI:10.1136/bmj.m1985.

9 Grasselli G, Greco M, Zanella A, et al. Risk Factors Associated With Mortality Among Patients With COVID-19 in Intensive Care Units in Lombardy, Italy. JAMA Intern Med 2020; published online July 15. DOI:10.1001/jamainternmed.2020.3539.

10 Zhou F, Yu T, Du R, et al. Clinical course and risk factors for mortality of adult inpatients with COVID-19 in Wuhan, China: a retrospective cohort study. The Lancet 2020; 395: 1054-62.

11 Gupta S, Hayek SS, Wang W, et al. Factors Associated With Death in Critically III Patients With Coronavirus Disease 2019 in the US. JAMA Intern Med 2020; published online July 15. DOI:10.1001/jamainternmed.2020.3596. 
medRxiv preprint doi: https://doi.org/10.1101/2021.10.29.21265687; this version posted October 30, 2021. The copyright holder for this preprint (which was not certified by peer review) is the author/funder, who has granted medRxiv a license to display the preprint in perpetuity. It is made available under a CC-BY-NC-ND 4.0 International license .

12 Gu T, Mack JA, Salvatore M, et al. Characteristics Associated With Racial/Ethnic Disparities in COVID-19 Outcomes in an Academic Health Care System. JAMA Netw Open 2020; 3: e2025197.

13 Gold JAW, Wong KK, Szablewski CM, et al. Characteristics and Clinical Outcomes of Adult Patients Hospitalized with COVID-19 - Georgia, March 2020. MMWR Morb Mortal Wkly Rep 2020; 69: 545-50.

14 Suleyman G, Fadel RA, Malette KM, et al. Clinical Characteristics and Morbidity Associated With Coronavirus Disease 2019 in a Series of Patients in Metropolitan Detroit. JAMA Netw Open 2020; 3: e2012270.

15 Mathew D, Giles JR, Baxter AE, et al. Deep immune profiling of COVID-19 patients reveals distinct immunotypes with therapeutic implications. Science 2020; 369. DOI:10.1126/science.abc8511.

16 Nguyen A, David JK, Maden SK, et al. Human Leukocyte Antigen Susceptibility Map for Severe Acute Respiratory Syndrome Coronavirus 2. Journal of Virology 2020; 94. DOI:10.1128/JVI.00510-20.

17 Horwitz LI, Jones SA, Cerfolio RJ, et al. Trends in Covid-19 risk-adjusted mortality rates in a single health system. medRxiv 2020; : 2020.08.11.20172775.

18 The RECOVERY Collaborative Group. Dexamethasone in Hospitalized Patients with Covid-19 - Preliminary Report. New England Journal of Medicine 2020; 0: null.

19 Richman IB, Taylor KE, Chung SA, et al. European genetic ancestry is associated with a decreased risk of lupus nephritis. Arthritis Rheum 2012; 64: 3374-82.

20 Freedman $\mathrm{BI}$, Langefeld $\mathrm{CD}$, Andringa KK, et al. End-stage renal disease in African Americans with lupus nephritis is associated with APOL1. Arthritis \& Rheumatology (Hoboken, NJ) 2014; 66: 390-6.

21 Clatworthy MR, Willcocks L, Urban B, et al. Systemic lupus erythematosus-associated defects in the inhibitory receptor FcyRIlb reduce susceptibility to malaria. Proc Natl Acad Sci $U$ S A 2007; 104: 7169-74.

22 Ness RB, Haggerty CL, Harger G, Ferrell R. Differential Distribution of Allelic Variants in Cytokine Genes among African Americans and White Americans. Am J Epidemiol 2004; 160: 1033-8.

23 Tharaux P-L, Pialoux G, Pavot A, et al. Effect of anakinra versus usual care in adults in hospital with COVID-19 and mild-to-moderate pneumonia (CORIMUNO-ANA-1): a randomised controlled trial. The Lancet Respiratory Medicine 2021; 9: 295-304. 
24 Novartis provides update on CAN-COVID trial in hospitalized patients with COVID-19 pneumonia and cytokine release syndrome (CRS). Novartis. https://www.novartis.com/news/media-releases/novartis-provides-update-can-covid-trialhospitalized-patients-covid-19-pneumonia-and-cytokine-release-syndrome-crs (accessed March 29, 2021).

25 Dinarello CA, Donath MY, Mandrup-Poulsen T. Role of IL-1beta in type 2 diabetes. Curr Opin Endocrinol Diabetes Obes 2010; 17: 314-21.

26 Charney AW, Simons NW, Mouskas K, et al. Sampling the host response to SARS-CoV-2 in hospitals under siege. Nature Medicine 2020; : 1-2.

27 Valle DMD, Kim-schulze S, Hsin-hui $\mathrm{H}$, et al. An inflammatory cytokine signature helps predict COVID-19 severity and death. medRxiv 2020; : 2020.05.28.20115758. 


\section{Figure Legends}

Figure 1: Flow diagram of included patients

Figure 2: Forest plots of multivariable logistic regression results predicting in-hospital mortality.

(A) All patients. (B) Stratified by race/ethnicity.

Figure 3: Forest plot of multivariable logistic regression results predicting in-hospital mortality using laboratory values, stratified by race/ethnicity. Models were adjusted for age, sex, and baseline hypoxia.

\section{Supplemental Materials}

Supplemental Table 1: Baseline demographic and clinical characteristics of patients presenting to the emergency department, by hospitalization status.

Supplemental Table 2: Baseline demographic and clinical characteristics of patients not admitted to the hospital, by race/ethnicity.

Supplemental Table 3: Self-reported ethnicities which were classified as (A) Hispanic, and (B) Non-Hispanic Black.

Supplemental Table 4: Univariable logistic regression using demographic and clinical factors to predict in-hospital mortality, stratified by race/ethnicity.

Supplemental Table 5: Univariable logistic regression using standardized laboratory values to predict in-hospital mortality, stratified by race/ethnicity. 
medRxiv preprint doi: https://doi.org/10.1101/2021.10.29.21265687; this version posted October 30, 2021. The copyright holder for this preprint (which was not certified by peer review) is the author/funder, who has granted medRxiv a license to display the preprint in perpetuity. It is made available under a CC-BY-NC-ND 4.0 International license.

Supplemental Table 6: Interaction p-values from multivariable logistic regression including interaction terms between race/ethnicity and demographic, clinical, or laboratory factors.

Supplemental Table 7: Multivariable logistic regression using standardized laboratory values to predict in-hospital mortality, stratified by race/ethnicity, adjusting for age, sex, and baseline hypoxia.

Supplemental Table 8: Median cytokine levels of patients from the University of Pennsylvania cohort. 
medRxiv preprint doi: https://doi.org/10.1101/2021.10.29.21265687; this version posted October 30, 2021. The copyright holder for this preprint (which was not certified by peer review) is the author/funder, who has granted medRxiv a license to display the preprint in perpetuity. It is made available under a CC-BY-NC-ND 4.0 International license.

Figure 1: Flow diagram of included patients

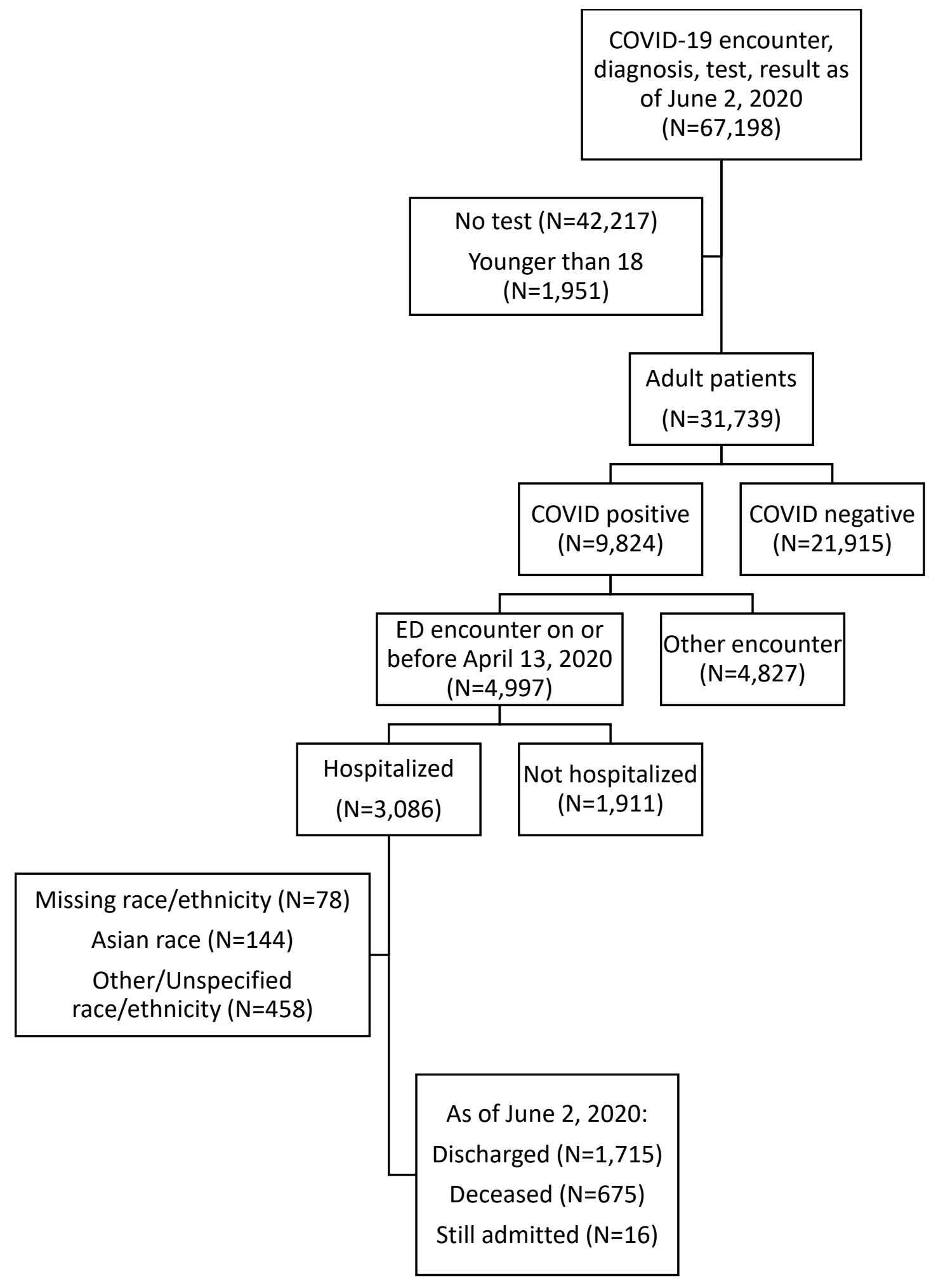


Figure 2: Forest plots of multivariable logistic regression results predicting in-hospital mortality. (A) All patients. (B) Stratified by race/ethnicity.

A

\section{Variable}

Male

Age (yrs)

Race: Non-Hispanic Black

Race: Hispanic

Manhattan facility

Hypertension

Diabetes

Coronary artery disease

Heart failure

Atrial fibrillation

Chronic kidney disease

COPD/asthma

Obesity

Cancer

Oxygen sat. $<92 \%$

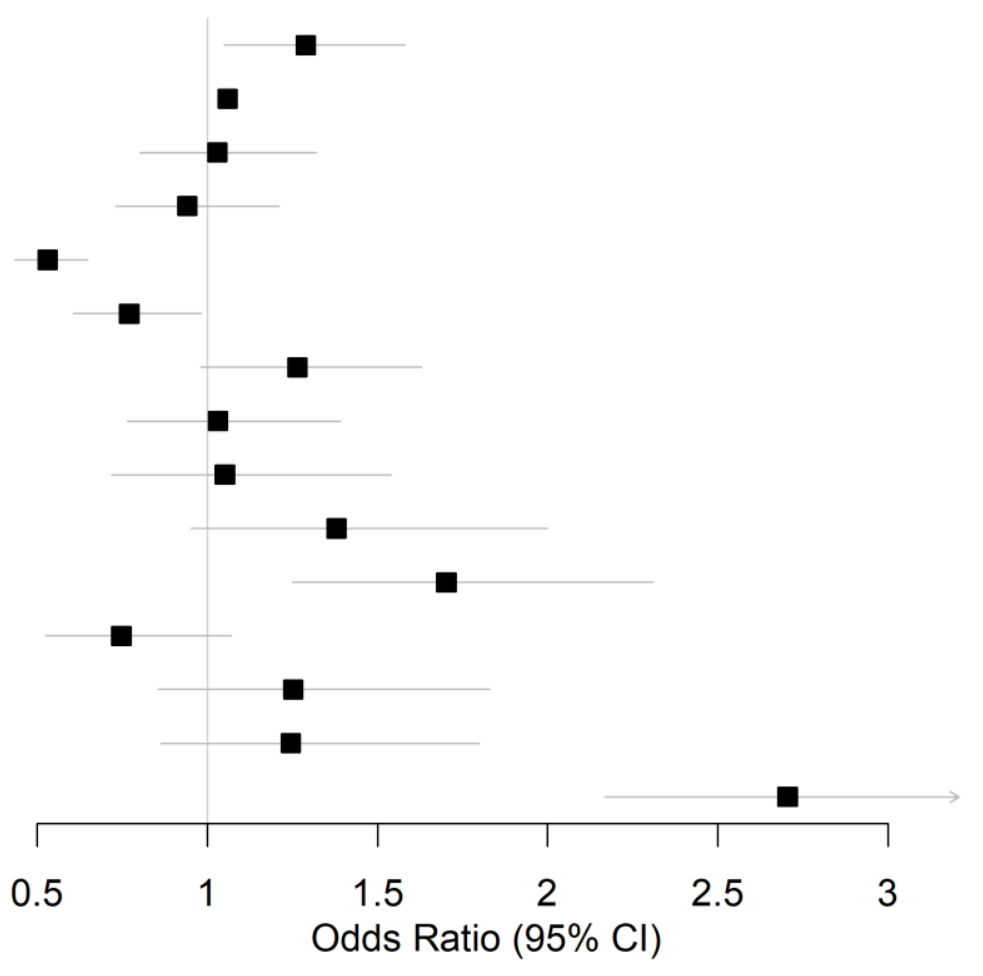


B

\section{NH White $\square$ NH Black $\square$ Hispanic}

\section{Variable}

Male

Age (yrs)

Manhattan facility

Hypertension

Diabetes

Coronary artery disease

Heart failure

Atrial fibrillation

Chronic kidney disease

COPD/asthma

Obesity

Cancer

Oxygen sat. $<92 \%$

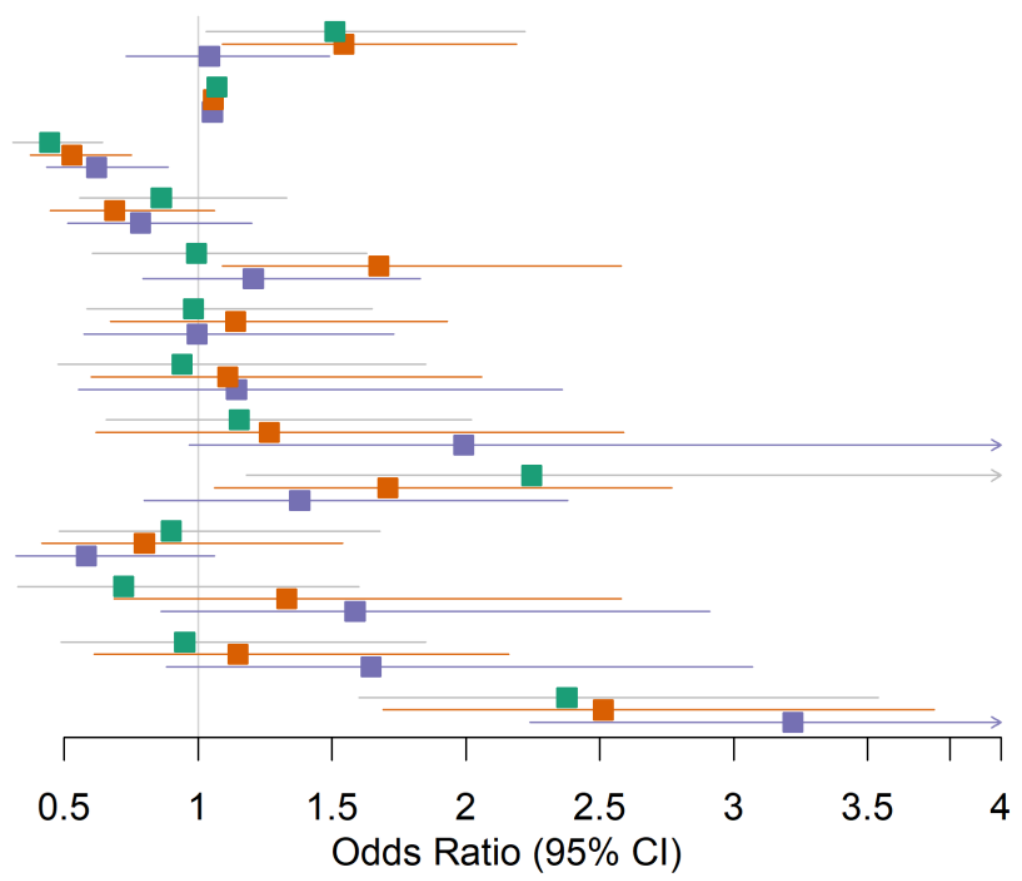


medRxiv preprint doi: https://doi.org/10.1101/2021.10.29.21265687; this version posted October 30, 2021. The copyright holder for this preprint (which was not certified by peer review) is the author/funder, who has granted medRxiv a license to display the preprint in perpetuity. It is made available under a CC-BY-NC-ND 4.0 International license.

Figure 3: Forest plot of multivariable logistic regression results predicting in-hospital mortality using laboratory values, stratified by race/ethnicity. Models were adjusted for age, sex, and baseline hypoxia. $\mathrm{NH}$ : Non-Hispanic.

\section{NH White $\square$ NH Black $\square$ Hispanic}

\section{Variable}

ALBUMIN

CRP

DDIMER

FERRITIN

IL1B

IL6

IL8

LDH

PROCALCITONIN

TNFa

WBC

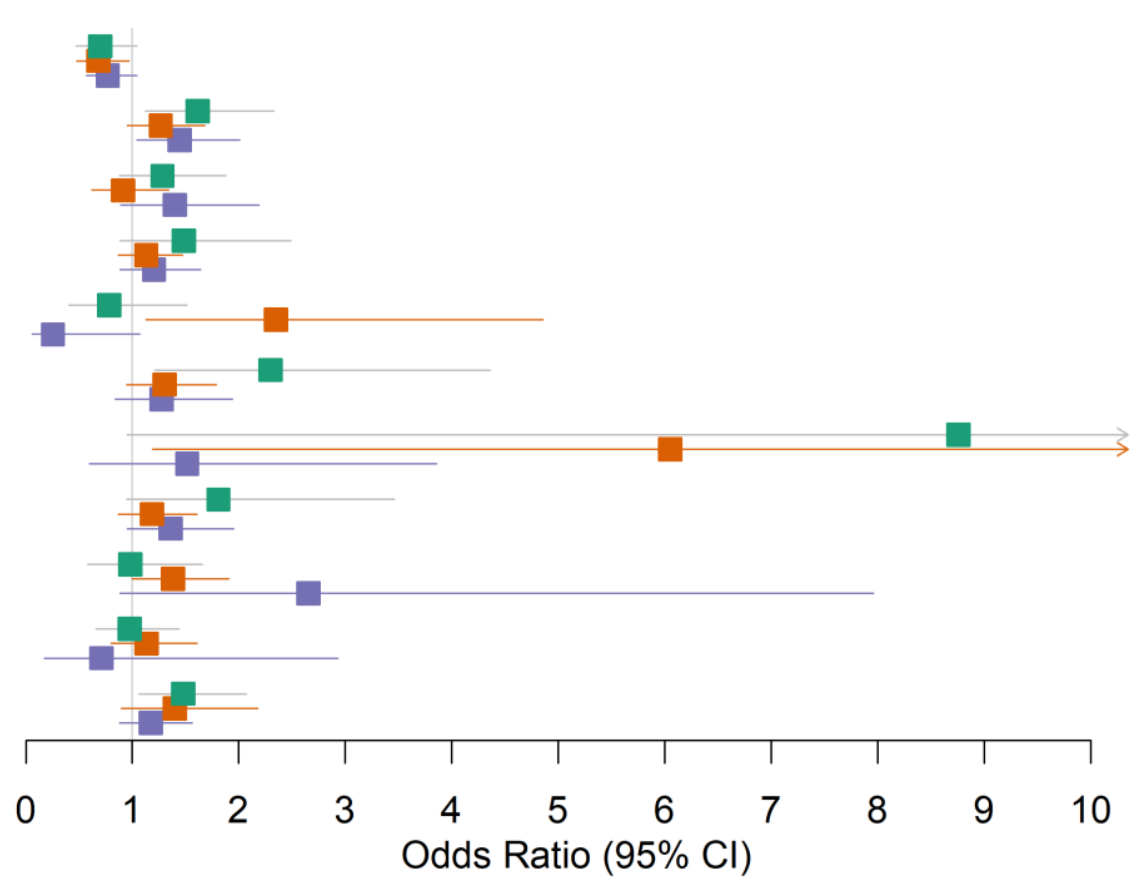

